\title{
A atividade litúrgico-musical no convento de Nossa Senhora dos Remédios de Évora: o seu papel na paisagem sonora da cidade durante o século XVII ${ }^{1}$
}

\author{
The liturgical-musical activity in the convent of Nossa Senhora dos Remédios of Évora: \\ its role in the city's soundscape during the seventeenth century
}

Luis Henriques ${ }^{1}$;

${ }^{1}$ E-mail:

luiscfhenriques@gmail.com CESEM/Universidade de Évora
Resumo: O convento de Nossa Senhora dos Remédios de carmelitas descalços está localizado no exterior das muralhas de Évora. O edifício atual fora das muralhas foi fundado no início do século XVII e viu uma atividade contínua, apesar de ter sido ocupado pelas tropas espanholas durante a Guerra da Restauração em 1663. A sua localização junto com a fundação recente trouxe uma atividade litúrgico-musical a uma parte relativamente sossegada da cidade. Seguindo os estudos sobre as paisagens sonoras das instituições religiosas, este estudo pretende retratar a implantação desta casa religiosa em Évora durante o século XVII focando atividade litúrgico-musical da comunidade e os eventos religiosos que ali tiveram lugar, rodeados por música. Ao mesmo tempo é dada atenção à uma inclusão da comunidade de carmelitas descalços na dinâmica religiosa da cidade, enquanto local de comunicação urbano através das procissões e outras festividades que tinham o convento como palco principal.

Palavras-chave: Carmelitas Descalços; Paisagem sonora histórica; Cantochão; Polifonia; Festas religiosas; Século XVII.

\begin{abstract}
The convent of Nossa Senhora dos Remédios of discalced Carmelites is located outside the walls of Évora. The actual building outside the walls was founded in the beginning of the seventeenth century and saw a continuous activity, although it was occupied by the Spanish troops during the War of the Restoration in 1663. Its location together with the recent foundation brought a liturgical-musical activity to a relative quiet part of the city. Following the studies in historical soundscapes of religious institutions this study aims to retrace the implantation of this new religious house in Évora during the seventeenth century focusing in the community's liturgicalmusical activity and the religious events that took place there that were surrounded by music.Atthe same time attention is given to the inclusion of the community of discalced Carmelites in the city's religious dynamic as a place of urban communication through the processions and other festivities that had the convent as a principal stage.
\end{abstract}

Keywords: Discalced Carmelites; Historical Soundscape; Plainchant; Polyphony; Religious Feasts; Seventeenth Century. 
O convento de Nossa Senhora dos Remédios foi uma casa religiosa de carmelitas descalços estabelecida em Évora no final do século XVI e que subsistiu em edifícios em dois locais distintos. O primeiro serviu de instalações provisórias na Rua do Raimundo, estabelecendo-se a comunidade posteriormente no edifício que ainda hoje se conserva no exterior da muralha fernandina, junto à Porta de Alconchel, à saída da cidade rumo a Lisboa. A implantação desta casa numa zona desocupada da cidade em termos de atividade litúrgico-musical surgiu praticamente como a implantação da ordem na cidade, e a sua relação com as outras ordens mendicantes aí já instaladas, nomeadamente os franciscanos e dominicanos.

A Ordem dos Carmelitas Descalços surgiu durante a segunda metade do século XVI como um movimento reformador da Ordem do Carmo. Teresa de Ávila e João da Cruz constituíram-se como os grandes impulsionadores de reforma, sendo considerados como os fundadores do movimento carmelita descalço. Os primeiros conventos reformados surgiram em Espanha a partir de 1562, data da fundação do convento de São José em Ávila, e 1568, ano em que abriu o primeiro convento em Duruelo (Vechina, 2000: 299). A 13 de julho de 1569 foi fundado o segundo convento em Pastrana, que serviria para o noviciado da reforma. Em 22 de junho de 1580 o breve Pia consideratione do Papa Gregório XIII declarava os carmelitas descalços como uma província separada, que teve como primeiro provincial o padre Jerónimo Graciano. Em 1593 foi reconhecida a total autonomia do ramo dos carmelitas descalços pelo Papa Clemente VIII, separando o seu carisma do ramo dos carmelitas da antiga observância, que desde então passaram a ser denominados como carmelitas calçados para distinção das duas ordens (Vechina, 2000: 299). O aparecimento desta ordem numa Espanha pós-tridentina em que os ideais da Contra-Reforma estavam muito presentes na evangelização teve um impacto nas comunidades religiosas, como na vida artística (onde se incluem as práticas musicais) que estava ligada a essa comunidade através da presença de um carácter profundamente místico nas obras de arte, quer se tratasse de pintura, escultura ou composição musical.

O movimento fundacional operado por Teresa de Ávila em Espanha nos primeiros anos de existência dos carmelitas descalços foi muito intenso, levando-a a importantes centros musicais começando pela própria cidade natal, até Toledo, Madrid, Salamanca, Sevilha, Málaga, Granada, entre outras cidades (Jiménez, 2016: 65). Ficou também alojada em instituições com uma intensa atividade musical. A sua exposição a esta atividade musical do siglo de oro espanhol certamente a terá influenciado, assim como a sua visão terá exercido influência nessas instituições. As casas religiosas femininas espanholas eram centros de intensa atividade musical, como é o caso, por exemplo, das casas carmelitas descalças em 
Granada (Ferrer, 2005: 126-127). Teresa de Ávila encontrou ao longo do seu percurso pelas diversas fundações uma paisagem sonora muito diversa. Nos seus escritos não se encontram relatos da passagem pelas catedrais das cidades onde fundou conventos, no entanto, travando contato com clérigos ligados a estas instituições (Jiménez, 2016: 72). Numa grande parte destes centros, nos quais se incluirão os carmelitas descalços, foram mantidas as tradições litúrgicas no respeitante à prática do cantochão pré-tridentino. A este respeito referiu Teresa de Ávila que nos ofícios diários "jamás sea el canto por punto, sino en tono, las voces iguales. Lo ordinário sea todo rezado y también la misa” (Jiménez, 2016: 73). Esta indicação implicava uma recitação dos textos litúrgicos a partir do Breviário da forma mais simples de interpretação, segundo uma fórmula de recitação, assim como a missa, talvez com o intuito de agilizar as celebrações musicais, como é costume das ordens dedicadas à evangelização.

Em termos de relações musicais, o compositor de polifonia vocal mais destacado da segunda metade do século XVI associado aos primeiros anos de existência dos carmelitas descalços e, em particular, a Santa Teresa de Ávila foi certamente Tomás Luis de Victoria (1548-1611). Estudos recentes demonstraram que ambos não se terão cruzado em vida adulta de Victoria, uma vez que estavam separados por uma diferença de 33 anos (Santa Teresa havia nascido em 1515 e Victoria em 1548). Porém, sendo estas duas importantes figuras do final do século XVI naturais da cidade de Ávila, onde viveram até à idade adulta, é muito provável que se tenham cruzado nesta cidade durante o período de infância do compositor em que o mesmo servia na Catedral (Ciffré, 2012: 104-105). Embora não estando documentado qualquer encontro entre ambos, não seria de admirar que se tivessem cruzado no círculo eclesiástico da cidade ou por intermédio dos familiares de Victoria, como é o caso do seu tio, Juan Luis de Victoria, cónego da Catedral de Ávila (Jiménez, 2016: 71-72). Em todo o caso, a figura mística de Santa Teresa terá certamente exercido alguma influência na composição musical de Victoria.

Os carmelitas descalços chegaram a Portugal sob a orientação de Fr. Ambrósio Mariano de São Bento em 1581, tendo fundado convento em Lisboa nesse ano. A vinda desta primeira comunidade terá estado relacionada com o contacto mantido entre D. Teotónio de Bragança, que na altura estudava na Universidade de Salamanca, e a própria Teresa de Ávila (Vechina, 2000: 299). Com Fr. Ambrósio veio Fr. Gaspar de São Pedro, proveniente do convento de Pastrana, Fr. João Evangelista e mais cinco religiosos (Santa Ana, 1657: 78). Instalados provisoriamente em casas que haviam alugado, passaram ao novo convento a 14 de outubro de 1581. Primeiramente, organizou-se uma solene procissão de grande aparato, rejeitada pelos 
religiosos por ir contra os ideais de pobreza da ordem. Desta forma no dia seguinte foi colocado o Santíssimo Sacramento na igreja do novo convento, pregando Fr. Gaspar de São Pedro, dizendo-se uma "missa cantada com excellente musica" (Santa Ana, 1657: 83). Assim, embora rejeitando o aparato e ostentação pública presenta na procissão que se organizava, os religiosos abraçaram um cerimonial litúrgico-musical de grande pompa, sugerindo-se que a "excellente musica" fosse mais que o regular cantochão, nomeadamente polifonia.

O convento dos carmelitas calçados foi um importante centro musical em Lisboa. No caso dos carmelitas descalços, não se conhece uma figura ligada à prática musical polifónica na centúria de seiscentos. Em Portugal, Fr. Manuel Cardoso foi muito provavelmente o compositor mais destacado do século XVII que se pode relacionar com a Ordem do Carmo, neste caso, com os carmelitas calçados. Este compositor, nascido em Fronteira no ano de 1566, estudou no Colégio dos Moços do Coro da Sé de Évora, tendo professado no convento do Carmo de Lisboa onde, para além de mestre de capela e organista, foi também vice-prior desta instituição (Henriques, 2016: 38-41). Não está confirmada a relação de Cardoso com o convento carmelita eborense, muito menos com o de Nossa Senhora dos Remédios, não sendo de excluir a relação e conhecimento da sua obra por estas casas eborenses. Aliás, a relação de polifonistas com o convento de Nossa Senhora dos Remédios existiu ao longo do todo o século XVII, como mais adiante se verá. Porém, nas reduzidas fontes documentais provenientes do convento eborense, não se encontram quaisquer referências à prática de música polifónica ao longo do século XVII, o que não seria de estranhar dado o reduzido número de religiosos que o convento de Nossa Senhora dos Remédios albergou desde a sua fundação, assim como o voto de pobreza e simplicidade.

O atual edifício do convento de Nossa Senhora dos Remédios foi construído numa zona da cidade relativamente despovoada no respeitante a casas religiosas. Para além de uma capela dedicada a Nossa Senhora da Ajuda, que estava localizada por cima da Porta de Alconchel (Barata, 1909: 59) e cuja atividade musical seria reduzida ou até mesmo inexistente, a grande instituição religiosa mais próxima era o convento de Santa Clara, de freiras clarissas. Esta casa foi fundada em meados do século XV pelo Bispo D. Vasco Perdigão, desenvolvendo-se a fundação no tempo do seu sucessor, o Bispo D. Jorge da Costa, apenas conhecendo a configuração arquitetónica atual em pleno século XVI, com a refundação da capela-mor da igreja, sendo, no entanto, estas obras anteriores ao convento dos carmelitas descalços (Fonseca, 1728: 388). 
O convento de Nossa Senhora dos Remédios de carmelitas descalços situa-se, assim, em frente à Porta de Alconchel, no exterior da muralha fernandina (cerca nova), a última a ser construída em torno da cidade de Évora. O convento ficou "contiguo aos muros da Cidade [...]. O sitio he aprazivel, e alegre, a Igreja magnifica, e o edificio taõ devoto, como aceado, cauzando singular devoçaõ o silencio, a modéstia, com que se vive no recinto destes Claustros" (Fonseca, 1728: 378). Estas são as palavras com que o Padre Francisco da Fonseca abriu o capítulo dedicado ao convento na sua obra Évora gloriosa, impressa em Roma no ano de 1728. Entre os adjetivos utilizados por este padre jesuíta, destaca-se a caraterização da instituição como silenciosa, ou seja, um local calmo aparentemente sem o grande rebuliço do mundo secular, certamente conferido pela localização exterior às muralhas. Todavia, este foi talvez o convento da cidade de Évora que maior rebuliço conheceu no primeiro século da sua existência.

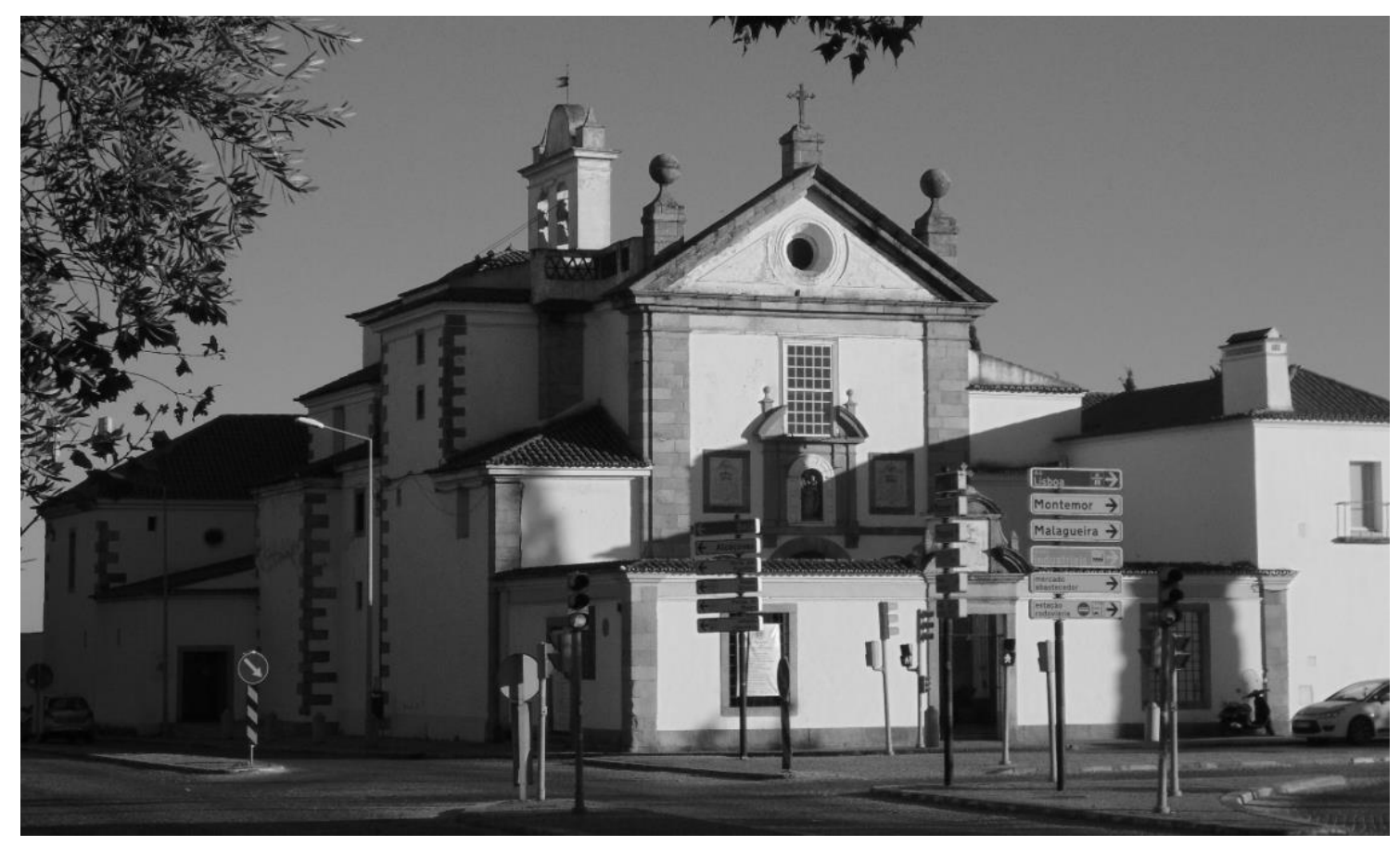

Imagem 1: Convento de Nossa Senhora dos Remédios de Évora (Foto: Luis Henriques)

A chegada dos primeiros carmelitas descalços a Évora foi referida pelo Padre Francisco da Fonseca na sua Évora gloriosa. Segundo o autor, o Arcebispo D. Teotónio de Bragança, que havia contactado pessoalmente com Santa Teresa de Ávila, e com quem trocava correspondência, ao saber da confirmação da sua reforma em 1562, ofereceu-lhe a fundação em Évora de um convento masculino e um feminino daquela ordem. O pedido terá sido feito pouco antes de 1579, uma vez que, segundo o autor de Évora gloriosa, o mesmo foi 


\section{pontéditora}

confirmado por carta da própria Santa Teresa, datada de 16 de janeiro de 1579 (Fonseca 1728: 379). Para o efeito foram enviados a Évora dois religiosos da ordem (cujos nomes não são mencionados por Fonseca) e a Madre Maria de S. José. Porém, não houve seguimento na fundação dos ditos conventos apontando Fonseca como motivo principal estar D. Teotónio ocupado na construção do mosteiro da Cartuxa, que decorreu de 1587 a 1598. Certamente que a construção da Cartuxa de Évora, assim como todas as outras obras de menor dimensão que realizou nas igrejas paroquiais da cidade, consumiram imensos fundos debilitando qualquer outro investimento em duas novas casas religiosas. Os primeiros carmelitas descalços acabaram por se estabelecer em Lisboa, como anteriormente referido em 1581. Mais tarde, após novo pedido do Arcebispo, enviou o Provincial, Fr. Agostinho dos Reis, os religiosos Fr. Jerónimo de S. Hilário e Fr. António de S. Francisco a Évora a fim de avançarem com a fundação do primeiro convento.

A 9 de novembro de 1594, os frades entraram na posse da ermida de Nossa Senhora dos Remédios, situada na Rua do Raimundo, assim como algumas casas e um hospital anexos, que haviam sido deixados ao Arcebispado pelos ermitães Fr. Aleixo e Fr. Domingos (Fonseca, 1728: 379). Com Fr. Jerónimo e Fr. António veio ainda para Évora um segundo grupo composto pelos religiosos Fr. Gaspar dos Reis, Fr. Eliseu de S. Ângelo, Fr. Diogo da Santíssima Trindade e Fr. António do Sacramento. Foram estes os primeiros seis religiosos que asseguraram a celebração das missas e ofícios no primeiro local em torno da ermida na Rua do Raimundo até à sua transferência para o edifício atual no exterior das muralhas (Fonseca, 1728: 379).

Pouco se sabe sobre a atividade na primeira casa da Rua do Raimundo no período anterior à fundação do convento extramuros, supondo-se que a comunidade seguisse as determinações da Regra primitiva da Ordem. Segundo a Regra, o ofício de Matinas deveria ser cantado à meia-noite, salvo raras exceções que obrigassem ao contrário. Seguindo o costume da ordem, exceção deveria ser feita a toda a oitava da festa de Corpus Christi, do Triduum Sacrum, vários dias do Tempo Pascal, Pentecostes, Circumcisão, Epifania e Natal, em que deveria ser cantado às dez e meia da noite (Anónimo, 1604: 8v). Estavam também incluídas nesta exceção festas do ciclo do Santoral importantes no calendário da ordem como a festa de São José, de Nossa Senhora do Carmo, e as festividades marianas da Assunção e Conceição, de São Bartolomeu, Santo Elias (Anónimo, 1604: 9). Para as outras festividades duplex, semiduplex e feriais celebrava-se o ofício à meia-noite cantando apenas o Invitatório, o Hino e o Te Deum laudamus, sendo as restantes rubricas possivelmente rezadas, de forma a abreviar a 
sua duração de forma a não exceder uma hora e um quarto. O ofício de Vésperas, quando rezado, não deveria exceder meia hora e, cantado, deveria demorar três quartos de hora. Os ofícios de Prima e Completas deveriam ser rezados num quarto de hora. As horas menores (Terça, Sexta e Nona) deveriam demorar menos de um quarto de hora. Existem ainda menções ao officium parvum de Nossa Senhora, que deveria ser rezado pausadamente, e a Missa Conventual, que quando cantada, deveria durar uma hora, se a solenidade não pedisse mais tempo (Anónimo,1736: 35). Através destes exemplos, percebe-se a preocupação em não prolongar demasiado as celebrações diárias, libertando assim tempo para as atividades oficinais do convento assim como para o serviço de evangelização.

Em todos os Sábados, após a hora de Prima, deveria cantar-se uma missa solene de Nossa Senhora, fazendo duas comemorações: do Espírito Santo e de São José, uma vez mais, de forma breve que não deveria exceder o tempo despendido na celebração da missa conventual (Anónimo, 1736: 37).Ainda no início do século XVIII surge determinado que o canto deva ser realizado com a devida gravidade segundo as recomendações dos Santos Padres, privilegiando o canto não figurado, ou seja, o cantochão (Anónimo, 1736: 33).

O número reduzido de religiosos por cada casa era advogado por Santa Teresa argumentando que mais valiam poucos perfeitos num convento que muitos imperfeitos. Assim, o número de religiosos por convento deveria ser o necessário para assegurar o funcionamento de casa (Jesus, 1661: 508-509). Teresa de Ávila estabeleceu o número de religiosos em doze, repartindo as atividades da casa entre si. Desta forma, um religioso deveria ter a seu cargo a portaria do convento, outro a enfermaria, a horta, e assim sucessivamente. Contudo, todos teriam obrigação de coro, isto é, de cantar as horas do dia litúrgico. Estes religiosos deveriam dirigir-se ao coro no primeiro toque do sino e estarem reunidos antes do último toque em todas as horas do dia ou da noite, para assim rezarem o Ofício Divino segundo o uso da Igreja Romana.

A Regra primitiva recomendava ainda que no convento onde pudessem comodamente assistir no coro seis religiosos, estes estariam obrigados a cantar todas as horas canónicas, tanto diurnas como noturnas. Era recomendada a existência no convento de pelo menos oito religiosos habilitados a cantar, sendo suficientes seis religiosos para cantar a missa conventual (Anónimo, 1604: 10). É este o número de religiosos que irão aparecer numa nota à margem presente no Livro das profissões e contractos do convento de Nossa Senhora dos Remédios de Évora (Biblioteca Pública de Évora, Códice CXXVI/2-22, f. 25v) em que, por ordem do Capítulo Geral de 1604, foi ordenada a queima de inquirições referentes a oito coristas e 
outros irmãos de vida ativa. Estas notas referem-se aos religiosos Fr. Afonso dos Anjos, Fr. Bartolomeu de Jesus, Fr. Sebastião de São Cirilo, Fr. António das Chagas, Fr. Domingos de Santo Alberto e Fr. António da Purificação, que constam como tendo professado segunda vez (as segundas profissões foram anotadas entre os fólios 20v e 25v). A nota foi assinada por Fr. Tomás de São Cirilo, Fr. Manuel de Jesus, Fr. Tomás de S. Ângelo e Fr. Simão dos Anjos. Isto significa que por volta de 1604, a casa carmelita descalça de Évora contava com oito religiosos que tinham a seu cargo o serviço do coro, isto é, o canto dos vários ofícios diários e outras cerimónias que exigissem o cantochão.

Segundo nota no final do Breviário, que contém o ciclo do Santoral próprio da Ordem (1630), os carmelitas descalços adotaram o Breviário Romano para o ciclo do Temporala 20 de junho de 1609, sendo o ciclo do Santoral incluído num volume próprio. Entre as festas do ciclo do Santoral destacavam-se o Santíssimo Sacramento (Corpus Christi), do Santíssimo Nome de Jesus e Maria, assim como ofícios próprios para as oitavas das festas da Apresentação até à Visitação. Durante o Advento seriam cantadas antífonas próprias da Ordem (Anónimo, 1630: 6). Deste modo, a festa do Santíssimo Sacramento (que designada a festa de Corpus Christi) deveria ser celebrada na quinta-feira após o Domingo da Santíssima Trindade com ofício de nove lições semiduplex. Privilegiar-se-ia a oitava e, caso ocorressem festas de segunda classe, estas deveriam ser transferidas para o dia seguinte. Se a festa ocorresse fora do Tempo Pascal dever-se-ia omitir o alleluia dos versos e responsórios e as lições do primeiro nocturno do ofício de Matinas deveriam ser aquelas das escrituras para o dia em questão e, caso ocorresse durante o Tempo Pascal, para além de adicionar o alleluia, os três salmos de cada noturno deveriam ser cantados com apenas uma antífona (Anónimo, 1630: 6). Todos os Sábados do Ano, até à última semana do Advento, deveria fazer-se a comemoração da Virgem Maria com antífonas próprias que seriam cantadas no ofício de Laudes, fazendo-se o ofício de comemoração mariana semiduplex. Durante o Advento e na festa da Anunciação, as lições do primeiro noturno do ofício de Matinas deveriam ser retiradas das Escrituras indicadas para o dia (Anónimo, 1630: 7). Muito possivelmente seria cantado com mais regularidade pela comunidade carmelita descalça de Évora o ofício comemorativo da Virgem Maria, celebrado ao Sábado como atrás mencionado.

No ofício de Vésperas entre o Sábado antes do Primeiro Domingo do Advento até ao ofício de Completas da festa da Purificação da Virgem deveria cantar-se a antífona Alma Redemptoris mater; após a festa da Purificação da Virgem até Quinta-Feira Santa deveria cantar-se a antífona Ave Regina caelorum; durante o Tempo Pascal, a antífona Regina caeli laetare; e 
entre o ofício de primeiras Vésperas da festa da Trindade até ao ofício de Nona do Sábado antes do Advento deveria cantar-se a antífona Salve Regina.Apesar da grande extensão deste ofício - um dos vários que seriam cantados pela comunidade - crê-se que a interpretação musical de uma grande percentagem das rubricas musicais seria realizada em recto tono. Esta era uma prática performativa do cantochão muito associada às comunidades religiosas que surgiram no âmbito da devotio moderna na qual se inserem os carmelitas descalços. As ordens religiosas que surgiram durante o século XVI viram grande parte dos ofícios reduzidos a esta forma de interpretação que consiste no canto do texto sobre uma corda de recitação musical. A celebração dos ofícios tornou-se assim um dever institucional a ser realizado de forma eficiente, de modo a libertar tempo para a meditação e oração, assim como para as tarefas comunitárias e ainda o trabalho religioso no exterior do convento (Reid, 2016: 136, 515).

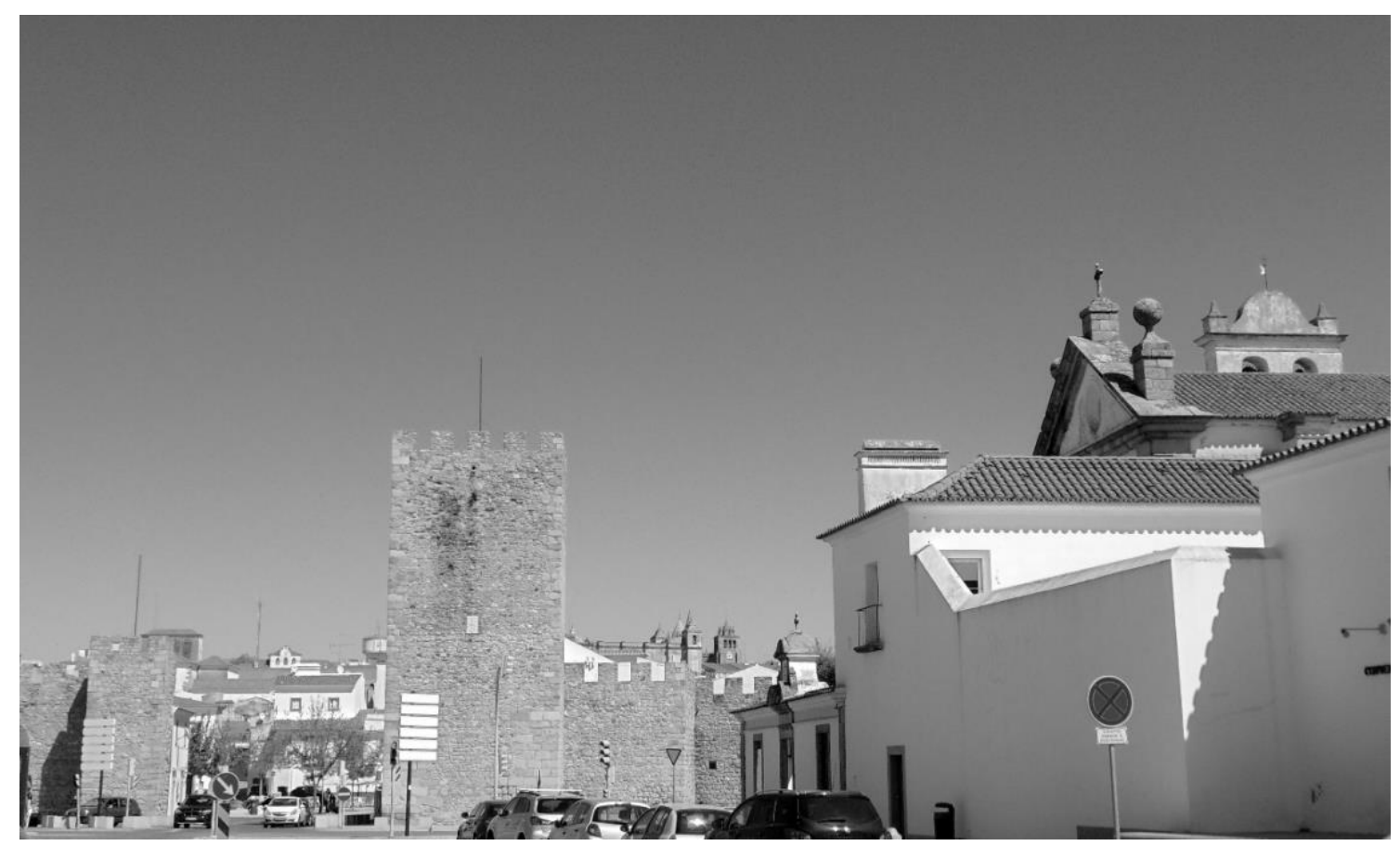

Imagem 2: Perspetiva atual do convento para a Porta e Rua de Alconchel (Luis Henriques)

Destacam-se vários momentos na vida musical da comunidade de Nossa Senhora dos Remédios, assim como da sua zona envolvente, ao longo do século XVII. O primeiro desses momentos foi a mudança da comunidade da Rua do Raimundo para a Porta de Alconchel. Por sugestão do prior Fr. José de São João, o Capítulo havia determinado, em 12 de abril de 1601, a compra de um terreno (uma horta com ferragial) que pertencia a D. Violante de Noronha para a construção do novo convento (Santa Ana, 1657: 445). O terreno foi comprado ainda no mesmo mês após a licença do Visitador Geral, Fr. José de Jesus Maria, com data de 15 de 


\section{pontéditora}

fevereiro de 1602. A escolha desta localização terá tido como motivo principal a sua instalação numa zona ainda não ocupada pela construção urbana da cidade. O espaço intramuros encontrava-se já demasiado preenchido com muitas casas religiosas, constituindo o espaço exterior um local aproximado aos desertos com uma cerca ampla onde poderiam construir ermitérios, como foi o caso do deserto construído no Buçaco algumas décadas mais tarde (Borges, 2011: 198). Certamente que as condições de Évora seriam muito melhores que as de Buçaco, mas o ideal de afastamento do interior da cidade constituiu uma motivação central em ambos os casos, procurando uma zona para meditação. Atualmente a antiga cerca do convento foi completamente ocupada, vendo-se, porém, ainda vestígios deste tipo de espaços eremitas, neste caso de religiosos capuchos, na cerca do antigo convento do Bom Jesus em Valverde preenchida com uma série de pequenas ermidas e ermitérios.

Abandonando Fr. José de São João o cargo de prior em maio de 1602, sucedeu-lhe Fr. Pedro de São José o qual lançou a primeira pedra do edifício dando início à sua construção (Santa Ana, 1657: 446). Em 1606 o prior Fr. Tomás de S. Cirilo, seu sucessor, concluiu dois dormitórios que permitiam já albergar os religiosos em comunidade. Após ter participado no Capítulo Provincial em Sevilha, resolveu-se iniciar a mudança da comunidade para o novo edifício.

A 25 de novembro de 1606, pelas cinco horas da tarde, levaram os religiosos a imagem de Nossa Senhora dos Remédios, que se dizia milagrosa, da ermida onde se encontrava na Rua do Raimundo para o novo convento em grande secretismo, sendo colocada no respetivo altar. A imagem foi, assim, transportada coberta num tabuleiro, carregando-a ao ombro Fr. Damião de Jesus Maria, saindo da cidade pela Porta do Raimundo, dirigindo-se para o novo convento pelo exterior da muralha. Aqui, entrou com o prior Fr. Tomás de São Cirilo e doze religiosos que para ali tinham convergido do interior da cidade por vários caminhos. A imagem foi em seguida colocada no altar, cantando a comunidade o hino Te Deum laudamus, muito provavelmente em cantochão, sendo interpretado em alternatim o hino, como era prática comum deste género, dividindo-se os religiosos em dois grupos, cantando o primeiro os versos ímpares do hino e o segundo os versos pares (Santa Ana, 1657: 447). No dia seguinte, 26 de novembro de 1606, foi levado o Santíssimo Sacramento para o novo convento. Consistiu numa cerimónia de grande aparato, que envolveu as altas esferas eclesiásticas da cidade. Por ser Domingo, grande parte da população da cidade e do termo compareceu na procissão de transferência do Santíssimo Sacramento, que foi levado pelo deão Diogo de Miranda Henriques, acompanhado pelos membros do Cabido e restantes clérigos da Catedral, 
participando também os religiosos do convento do Carmo. Disse o deão a missa na igreja provisória, criada num dos dormitórios, uma vez que a actual igreja só foi sagrada anos mais tarde, pregando ainda o prior Fr. Tomás de S. Cirilo (Santa Ana, 1657: 447). A igreja do convento, possivelmente ainda em início de construção em 1606, foi terminada apenas em 1614, sendo prior do convento Fr. António do Sacramento. O Arcebispo D. José de Melo foi quem, em 1614, a sagrou, assistindo também à missa comemorativa da recente beatificação de Santa Teresa, que ocorrera a 24 de abril desse ano pelo Papa Paulo V (Santa Ana, 1657: 448). Aqui, será importante referir o cerimonial litúrgico-musical dos carmelitas descalços para a dedicação da igreja que surge geralmente no final do Antifonário e Gradual, no volume correspondente ao ciclo do Temporal. Como anteriormente mencionado, os carmelitas descalços seguiam no início do século XVII o Breviário Romano reformado para este ciclo do Ano Litúrgico sendo, assim, de supor que o ofício de dedicação da igreja fosse proveniente desta fonte litúrgica. Desta forma, o ofício encontra-se estruturado de acordo com o Antifonário Romano, com a sequência usual dos vários ofícios diários. Assim, o ofício de Vésperas seria composto musicalmente por cinco antífonas, hino e antífona ad Magnificat, o hino de Completas, as antífonas de Vésperas seriam repetidas no ofício de Laudes junto com o hino próprio e a antífona ad Benedictus, para as horas seguintes repetia-se as antífonas de Vésperas, que também seriam repetidas no ofício de segundas Vésperas junto com a antífona ad Magnificat própria para este ofício.

Uma das figuras mais importantes ligadas ao convento de Nossa Senhora dos Remédios durante o século XVII foi o Arcebispo D. José de Melo. Natural de Évora, passou por Roma, sendo Bispo de Miranda antes de ter sido nomeado Arcebispo de Évora, cargo que ocupou desde 1611 a 1633 (Barata, 1874: 32). Em 1617, este prelado mostrou intenção de ser sepultado na igreja assim como de ficar com o padroado do convento. O Vigário Geral da ordem, Fr. Afonso dos Anjos, enviou licença do Definitório celebrado em Alcalá de Henares a 21 de maio de 1625 autorizando a realização de escritura de contrato do padroado, que foi assinada a 21 de junho desse ano na presença de D. Francisco de Melo e do prior Fr. Frutuoso da Madre de Deus (Sacramento, 1721: 385). Segundo a escritura, ficou o Arcebispo encarregado de terminar a casa, fazendo o pórtico da igreja, novo refeitório, oferecendo livros para biblioteca do convento e ornamentos de todas as cores para a sacristia, assim como a "meter em casa a quantidade de agoa que el Rey lhe tinha concedido" (Santa Ana, 1657: 448). Havia ainda duzentos mil réis anuais para a celebração de seis missas diárias e três ofícios anuais. Ficou o convento obrigado a dar-lhe a capela-mor e o cruzeiro para sepultura e a 


\section{pontèditora}

celebrar-lhe as seis missas diárias e três ofícios pro defunctis anuais: um na oitava da festa de Todos-os-Santos, outro a 10 de dezembro (data em que havia sido batizado) e o último no dia em que morresse (Santa Ana, 1657: 448), o que veio a acontecer em 2 de fevereiro de 1633. Não ficou especificado se os três ofícios seriam cantados ou rezados. Porém, sendo o Arcebispo a figura central no padroado do convento, presume-se que fosse os três cantados. A celebração do officium defunctorum é uma das celebrações musicais extraordinária aos ofícios diários que eram cantados no convento, constituindo uma das rotinas litúrgico-musicais de praticamente todas as casas religiosas. Para além dos três ofícios anuais de D. José de Melo, encontram-se ainda o do seu sobrinho. Francisco de Melo, que havia deixado como obrigação a celebração de um ofício pro defunctis e uma missa cantada e outra rezada (Santa Ana, 1657: 449).

D. José de Melo deixou em testamento ao convento várias relíquias de santos que haviam sido trazidas de Roma. Estas conservavam-se na capela do Senhor Jesus, sendo expostas ao povo nos dias festivos. Foram recebidas pela comunidade do convento, cantando-se na sua chegada o hino Te Deum laudamus. Entre estas relíquias, destacavam-se as cabeças de Santo Apolónio e São Lúcio, que eram celebradas a 18 e 28 de abril respetivamente, com um ofício duplex que também seria certamente cantado pela comunidade (Sacramento, 1721: 388).

O evento que mais impacto exerceu na rotina do convento de Nossa Senhora dos Remédios durante o século XVII foi o cerco e consequente tomada de Évora durante a Guerra da Restauração. As tropas espanholas comandadas por D. Juan de Áustria chegaram às imediações da cidade a 14 de maio de 1663, tomando imediatamente os conventos e mosteiros exteriores à muralha. Para quartel da Corte foi ocupado o mosteiro de Nossa Senhora do Espinheiro e, para aquartelamento das tropas, mosteiro da Cartuxa e o convento de Santo António, cuja permanência das tropas espanholas terá certamente destabilizado - senão mesmo, interrompido - a celebração diária dos ofícios destas comunidades (Menezes, 1698: 518). As tropas portuguesas da cidade haviam ocupado o convento de Nossa Senhora do Carmo, junto à Porta da Lagoa, criando uma linha de comunicação com a cidade. Os espanhóis bombardearam o convento com artilharia, arrasando-o ao mesmo tempo que bombardeavam as muralhas da cidade, retirando-se os portugueses para a cidade com o terço do Algarve que o defendia, o mestre de campo Manuel de Sousa de Castro. A cidade caiu em poder dos espanhóis a 22 de maio. 
O convento de Nossa Senhora dos Remédios viu-se também no centro da ação, sobretudo devido à sua localização próxima da Porta de Alconchel. No plano de defesa da cidade havia sido ordenado que se barricassem todas as portas, à exceção da Porta de Alconchel, talvez por ser a porta onde terminava a estrada em direção a Lisboa. Esta decisão terá selado o destino do convento carmelita descalço, tendo sido também determinante na sua ocupação pelas tropas espanholas (Cunha, 1663:62-67). Na cerca do convento existia uma ermida fundada pelo prior Fr. Manuel da Trindade, que servia de retiro aos religiosos (ermitério), tendo sido destruída pelas tropas de D. Juan de Áustria, demolindo-a para no sítio se abrirem trincheiras (Sacramento, 1721: 386). Luís de Menezes relata que as tropas espanholas ao arrombarem as portas do convento, ficaram surpresos por verem todos os religiosos reunidos no coro com a maior tranquilidade a cantar o ofício. Porém, não se consegue encontrar mais informação para além desta breve e vaga nota de Menezes, o que também não permite determinar qual seria a hora do dia que os religiosos estariam a cantar. Das várias horas, uma parece não ter sido: o ofício de Matinas, uma vez que este ofício era cantado à meia-noite. Supõe-se, assim que pudesse ter sido Laudes, que era cantado ou nascer do sol, ou algumas das horas menores (Prima, Terça, Sexta ou Nona, que se cantariam durante o dia. Uma vez, que a chegada dos espanhóis a Évora ocorreu no dia 14 de maio, que no ano de 1663 caiu numa segunda-feira, estaria a comunidade a cantar um ofício ferial, bastante mais breve e simples que os ofícios solenes para festas de santos ou domingos e dias de maior importância na comunidade.

No dia 23, D. Juan de Áustria foi ouvir missa à Catedral, tendo sido recebido com a devida solenidade. Era por esta altura mestre de capela da Catedral o padre António Rodrigues Vilalva, cuja permanência em Évora durante este período carece ainda de confirmação, uma vez que o compositor passou algum tempo na cidade de Lisboa, não se precisando quando regressou a Évora (Henriques, 2017: 356).Estaria também presente o mestre da Claustra, cargo de grande importância no ensino musical, que por essa altura seria Bento Nunes Pegado, falecido em 1663 não se sabendo se em consequência dos confrontos entre as tropas espanholas e portuguesas (Alegria, 1973: 70). Terminado o ofício na Catedral, retirou-se D. Juan de Áustria para o palácio dos Condes de Basto. No dia seguinte, integrou a procissão do Corpus Christi junto com os oficiais e soldados do seu exército, mas o povo, temeroso ou rebelando-se contra os ocupantes, compareceu em reduzido número (Menezes, 1698: 519). Esta procissão era uma das mais importantes celebrada na cidade ao longo do ano, o que terá motivado a sua realização apesar da cidade estar envolvida num conflito bélico. A incorporação dos espanhóis na mesma procissão também terá significado uma atitude 
profundamente política e de demonstração de poder enquanto força ocupante da urbe alentejana, à qual respondeu população não comparecendo ao evento religioso como refere o Padre Fonseca, mas, ao mesmo tempo, também cívico. Não se conhecendo o itinerário da procissão de Corpus Christi em Évora, pressupõe-se que esta percorresse as principais artérias da cidade, nomeadamente a Rua de Alconchel, uma vez que esta era a principal entrada da cidade (a estrada proveniente da capital do reino terminava na respetiva porta), por onde costumavam entrar as mais altas individualidades, como foi o caso do próprio rei, restaurador da soberania portuguesa, D. João IV. Esta passagem por Alconchel, implicaria certamente também uma passagem pelo convento de Nossa Senhora dos Remédios, apesar do difícil momento que esta comunidade estaria a viver nesse momento.

Sendo o cantochão o repertório que ocupava a maior parte do tempo musical dos vários ofícios diários encontra-se pelo menos duas ocorrências no que diz respeito a relações entre compositores de canto d'órgão (entenda-se, polifonia) e o convento de Nossa Senhora dos Remédios. São estes compositores Diogo Dias Melgaz e um Fr. Simão dos Anjos, possivelmente Simão dos Anjos de Gouveia.

No Livro das profissões e contractos do convento (BPE, Códice CXXXVI/2-22) assina as profissões dos noviços entre os anos de 1603 a cerca de 1617 um Fr. Simão dos Anjos, que se presume ter ocupado o cargo de mestre dos noviços durante esse período, uma vez que é outro religioso a assinar o livro a partir dessa data. A associação deste Fr. Simão dos Anjos, religioso carmelita descalço, com Simão dos Anjos de Gouveia foi iniciada por José Augusto Alegria. Num estudo sobre a música na cidade de Évora (Alegria, 1944: 124), foi atribuída a Fr. Simão dos Anjos a autoria do motete Pueri Hebraeorum vestimenta presente num pequeno livro de coro conservado na Biblioteca Pública de Évora (Códice CLI/1-3, ff. 29v-30r). Para além desta obra, existe ainda em Évora uma versão de Jesu Redemptor, para a ladainha pro defunctis, num livro de cantochão que terá pertencido ao mosteiro hieronimita de Nossa Senhora do Espinheiro (Arquivo Distrital de Évora, Mús. Lit. 48, f. 33v). A associação de Simão dos Anjos de Gouveia à cidade de Évora foi estudada primeiramente pelo musicólogo Robert Stevenson (1982: XVII-XVIII) na introdução à edição do motete do Códice CLI/1-3. Baseado no que afirmou Diogo Barbosa Machado na sua Bibliotheca Lusitana (1752: 308), Gouveia estudou com Manuel Mendes na Claustra da Catedral de Évora. Por volta de 1600, havendo já professado na Ordem de São João Evangelista (Lóios), sucedeu a Pedro Thalésio (que passou a ocupar o cargo de Lente de Música na Universidade de Coimbra) como mestre de capela do Hospital de Todos-os-Santos em Lisboa. Em 1611 terá concorrido ao posto de 


\section{pontéditora}

Lente de Música na Universidade de Coimbra sem sucesso.

Embora as datas referidas não sejam incompatíveis com o percurso de Fr. Simão dos Anjos no convento de Évora, a sua profissão na Ordem de São João Evangelista levanta algumas dúvidas, assim como o serviço musical no Hospital de Todos-os-Santos, uma vez que Stevenson não apresenta fontes que possam corroborar esse percurso religioso e a atividade em Lisboa para além do testemunho de Barbosa Machado. A título de exemplo, o próprio Barbosa Machado refere um Fr. Simão de Gouveia, nascido em Lisboa que professou na Ordem de Santo Agostinho (Machado, 1752: 716-717), o que leva a crer que Simão dos Anjos fosse um nome de religião comum em várias ordens. A meia dúzia de obras que sobreviveram deste compositor surgem identificadas nas fontes como Simão dos Anjos ou Sinom ab Angelis. O nome Simão dos Anjos surge associado a duas obras, para além das duas de Évora, no Códice polifónico do mosteiro cisterciense de Arouca (Res. Ms. 032): o hino $O$ lingua mens (ff. 16v-17) e a um Alleluia (ff. 57v-58).

O livro de coro onde se encontra o motete Pueri Hebraeorum vestimenta possui também outras obras de Manuel Mendes, que terá sido mestre de Gouveia em Évora. O livro consiste em dois manuscritos agrupados e, a partir da identificação da marca de água, a sua cópia terá ocorrido por volta de 1615, para o caso da primeira metade e 1575, no caso da segunda (Alvarenga, 2011: 138). No caso da segunda metade do livro, composta por 27 responsórios de autor desconhecido para o Triduum Sacrum, foram encontradas concordâncias em manuscritos localizados em Óbidos, Coimbra e Porto. No caso da primeira metade, esta é composta por obras para a Quaresma, Domingo de Ramos e Tempo Pascal, de Manuel Mendes, Duarte Lobo, Simão dos Anjos e António de Oliveira (Alvarenga, 2011: 142). A proveniência do livro não foi ainda estabelecida, ficando assente que terá tido origem em Évora, sendo de supor que terá pertencido a uma capela musical de pequena dimensão, com cerca de quatro cantores, contrariamente às instituições de maior dimensão como a Catedral (Alvarenga, 2011: 148). Estas características adequam-se ao contexto musical do convento de Nossa Senhora dos Remédios, porém, não foram encontrados quaisquer outros pontos de uma possível ligação do livro à casa carmelita descalça para além do nome Simão dos Anjos.

Um outro compositor, cuja relação com o convento carmelita surge claramente identificada, foi o reitor do Colégio dos Moços do Coro, mestre da Claustra e mestre de capela da Catedral no final do século XVII Diogo Dias Melgaz. Melgaz nasceu em Cuba em 1638 e morreu em Évora na madrugada de 12 de março de 1700. Melgaz assumiu os três cargos da Catedral gradualmente, sendo afetado por doença que lhe terá diminuído a capacidade de os manter 
ainda em 1672 (Alegria, 1997: 139). A Irmandade de Santa Marta (dos Clérigos), à qual pertencia, fez-lhe as "obrigações de Irmão na forma do nosso estatuto" (BPE, Códice CXXVI/2-21, f. 184). Foi sepultado no alpendre da igreja do convento de Nossa Senhora dos Remédios. Estas obrigações consistiam no ofício pro defunctis, não só o ordinário da missa com o responsório Libera me, mas também os ofícios diários, nomeadamente os ofícios de Matinas e Laudes. Barbosa Machado refere um epigrama que lhe terá servido de epitáfio (Machado, 1759: 99):

\section{Flebili occubuit, qui scivit in orbe Magister \\ Caelestem Musam communicare viris. \\ At si funerea tandem jacet obrutus urna; \\ Non fama in tumulo contumulata jacet. \\ Aeternis vivet Melgaz post funera lustris \\ Donec erun homines, sydera donec erunt.}

Para além de ter sido sepultado no convento, mais nada se sabe sobre a relação de Melgaz com os carmelitas descalços de Évora, fechando assim o século XVII no respeitante às notícias de carácter musical relacionadas com o convento eborense.

Em suma, a integração do convento de Nossa Senhora dos Remédios de carmelitas descalços na paisagem sonora de Évora durante o século XVII divide-se em dois momentos fundamentais, os quais são separados por um período bélico da Guerra da Restauração. Embora breve, este conflito terá, contudo, trazido bastante violência à cidade perturbando e interrompendo a vida litúrgico-musical das comunidades religiosas, sobretudo aquelas localizadas fora dos muros da cidade. Assim, nas primeiras décadas do século XVII, após a chegada dos religiosos à cidade, assiste-se à fundação e consolidação do convento e a construção gradual do mesmo na localização atual junto à Porta de Alconchel, cuja zona era já ocupada pelo convento de Santa Clara, de freiras clarissas. Neste primeiro período a rotina litúrgico-musical terá seguido a Regra Primitiva, nomeadamente no que respeitava ao serviço do coro e a celebração das Horas diárias. Foram vários os momentos importantes na história deste convento, nomeadamente aqueles relacionados com o padroeiro, D. José de Melo, estando a música presente neles, sobretudo através do cantochão - repertório central nas comunidades religiosas - mas também possivelmente através da polifonia e uma provável relação do compositor Simão dos Anjos de Gouveia com a comunidade eborense nas 
primeiras décadas de seiscentos. Já no final do século XVII, desceu à sepultura no convento de Nossa Senhora Diogo Dias Melgaz, um dos grandes polifonistas eborenses, do qual não se conhece mais relações com a comunidade, para além de lhe terem dado morada eterna.

\section{Notas de rodapé:}

1 Este trabalho enquadra-se no âmbito do projeto de Doutoramento financiado pela FCT - Fundação para a Ciência e Tecnologia: "Polifonia portuguesa tardia: A problemática da continuidade na obra sacra de Diogo Dias Melgaz e Pedro Vaz Rego" (FCTSFRH/BD/131505/2017). 


\section{Referências bibliográficas}

Alegria, J. A. (1944). “A Música em Évora no século XVI (Tentativa de Esbôço Histórico). A Cidade de Évora, 7-8, 118-132.

Alegria, J. A. (1973). História da Escola de Música da Sé de Évora. Lisboa: Fundação Calouste Gulbenkian.

Alegria, J. A. (1997). O Colégio dos Moços do Coro da Sé de Évora. Lisboa: Fundação Calouste Gulbenkian.

Alvarenga, J. P. d' (2011). Manuscript Évora, Biblioteca Pública, Cód. CLI/1-3: Its Origins and Contents, and the Stemmata of Late-Sixteenth- and Early-Seventeenth-Century Portuguese Sources. Anuario Musical, 66, 137-158.

Anónimo (1630). Officia Propria Sanctorum... Carmelitarum pro fratribus discalceatis eiusdem ordinis. Veneza: Apud Iuntas.

Anónimo (1736). Regla Primitiva, y Constituciones de los Religiosos Descalzos de la Orden de Bienaventurada Virgen Maria de el Monte Carmello. Madrid: Por Don Miguel Francisco Rodriguez.

Anónimo (1604). Regvla Primitiva et Constitvtiones Fratrum Discalceatorum Ordinis B. Mariae de Monte Carmelo. Madrid: Apud Ioannem á Cuesta.

Barata, A. F. (1874). Esboços Chronologico-Biographicos dos Arcebispos da Egreja de Evora. Coimbra: Imprensa Litteraria.

Barata, A. F. (1909). Évora Antiga. Évora: Minerva Commercial.

Borges, C. (2011). Os Eremitas e o Ideal de Santidade no Imaginário Português: o

Deserto dos Carmelitas Descalços no séc. XVII. Lusitania Sacra, 23, 189-206.

Ciffré, J. M. (2012). Mvsica Caelestis: Reflexions sobre Música i Símbol. Tarragona: Arola Editors. 
Ferrer, M. J. (2005). La música en los conventos femininos de clausura en Granada. Granada: Universidad de Granada.

Fonseca, F. da (1728). Evora Gloriosa. Roma: Na Officina Komarekiana.

Henriques, L. (2017). A paisagem sonora de Évora no século XVII: Perspectivas a partir da actividade das instituições religiosas. Em Book of Proceedings II International

Congress on Interdisciplinarity in Social and Human Sciences(pp. 355-359).Faro: Research for Spatial and Organizational Dynamics.

Henriques, L. (2016). Nos 450 anos de Frei Manuel Cardoso. Glosas, 15, 38-41.

Jiménez, J. R. (2016). Fémina inquita y andariega: Paisajes sonoros del itinerário fundacional de Teresa de Jesús. EmEl Libro de la 55 Semana de Música Religiosa de Cuenca (pp. 63-89). Cuenca: Semana de Música Religiosa de Cuenca/Ediciones de la Universidad Castilla La Mancha.

Jesus, T. de (1661). Cartas de la Santa Madre Teresa de Iesvs. Antuérpia: En la Emprenta Plantiniana.

Machado, D. B. (1752, 1759). Bibliotheca Lusitana.Tomos III e IV. Lisboa: Na Officina de Ignacio Rodrigues.

Menezes, L. de (1698). História de Portugal Restaurado. Tomo II. Lisboa: Na Officina de Miguel Deslandes.

Reid, A. (2016). In Pursuit of Participation - Liturgy and Liturgists in Early Modern and PostEnlightenment Catholicism. Em Reid, A. (ed.). T\&T Clark Companion to Liturgy (pp. 133152). Londres: Bloomsbury.

Sacramento, Fr. J. do. (1721). Chronica de Carmelitas Descalços particular da Provincia de S. Filipe do Reyno de Portugal. Tomo II. Lisboa Occidental: Na Officina Ferreyrenciana.

Santa Ana, Fr. B. de (1657). Chronica de Carmelitas Descalços Particvlar do Reyno de Portugal. Tomo I. Lisboa: Na Officina de Henrique Valente de Oliueira.

Stevenson, R. (ed.). (1982). Antologia de Polifonia Portuguesa 1490-1680. Portugaliae Musica XXXVII. Lisboa: Fundação Calouste Gulbenkian. 
Vechina, J. C. (2000). Carmelitas Descalços. Em Azevedo, C. (dir.). Dicionário de História Religiosa de Portugal (pp. 297-300). Volume 1. Lisboa: Círculo de Leitores. 